\section{AFFORDABLE, LICENCE-FREE PAYMENT OPTIONS}

Looking to offer your patients affordable treatment finance, but not authorised by the Financial Conduct Authority (FCA)? Then look no further than Chrysalis Finance, the UK's only provider of affordable, licence-free dental treatment payment options. Available to all UK dental practices for a nominal monthly fee of $£ 8.50$, our expert team helps practices to become an Appointed Representative. Joining Chrysalis Finance means that practices can offer their patients the opportunity to spread the cost of dental treatment, making it more affordable and accessible to them. Plus, with Chrysalis Finance there's no need to be directly authorised by the FCA, as we'll happily take full responsibility for all compliance risks and regulations - so you can concentrate on dentistry.

By following a quick and simple '123' application process, Chrysalis practices receive full payment within 48 hours of a patient being approved, effectively improving your cashflow. In as little as 24 hours we can set you up to start offering Chrysalis dental funding, helping your patients to say 'yes' to treatment and successfully increasing your turnover and sales of higher value treatments.

For more information visit Chrysalis Finance at The Dentistry Show 2015 stand E55, or if you are unable to attend call 03333232230 or visit www.chrysalisfinance.com.

\section{SHARED PARENTAL LEAVE IN A NUTSHELL}

Much has been made of the new Shared Parental Leave (SPL) rights which will be available for parents whose child is either born or placed after 5 April 2015. So what does it mean for employers and parents?

Many readers may be familiar with the current statutory and parental rights. The new SPL will essentially allow mothers and fathers to share leave, though compulsory leave for mothers and fathers will remain at the current two weeks. The qualifying service requirements and length of leave (52 weeks) will remain the same.

So in a nutshell the changes will be:

1. Parents adopting children will be entitled to statutory payments

2. The new right is more flexible: a mother or primary adopter can either return to work or curtail leave without sacrificing the remainder of their leave

3. It will be possible for both parents to take SPL concurrently.

Contact SCE Solicitors for details of our free seminar on the topic on 01133504030 or at info@ scesolicitors.co.uk.

\title{
GREATEST POSSIBLE CONTRAST, LOWEST POSSIBLE DOSE
}

On the proven ORTHOPHOS XG platform, Sirona has developed an X-ray system with innovative imaging technology for the greatest possible contrast with the lowest possible dose. It is available as an upgradable $2 \mathrm{D}$ version or as a $3 \mathrm{D}$ hybrid unit with a large volume $(11 \times 10 \mathrm{~cm})$ or an $8 \times 8 \mathrm{~cm}$ volume especially optimised for a general dental practice.

Sharp layer technology uses several thousand individual projections for one panoramic image, which are

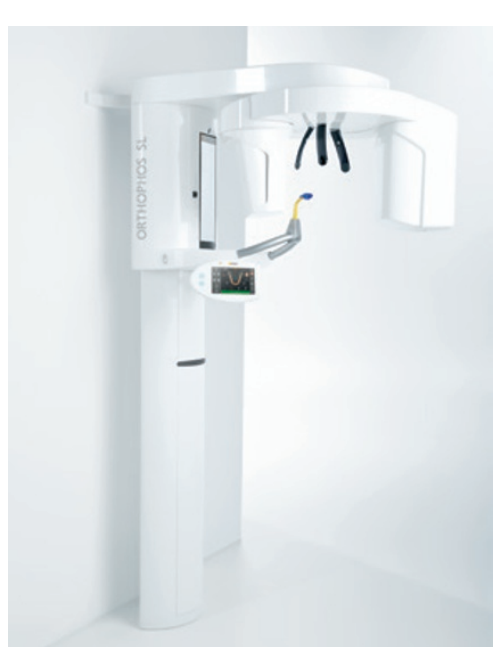

taken very rapidly from several angles in one rotation and reproduce the individual morphological situation very sharply. Its advantages: excellent panoramic images and the possibility of compensating for positioning errors retroactively.

The automatically implemented sharp layer technology intelligently adapts the sharp layer and does away with the necessity for the advance selection of jaw morphology and front tooth position, thus simplifying the operation of the X-ray unit. The second innovation allowing for a completely new level of image quality is the direct conversion sensor (DCS). It generates electrical signals directly from the X-ray beams without, as in the past, the intermediate step of first converting them to light. This means that less information is lost and the image data yielded are significantly better in relation to the applied dose.

For further information call 08450715040 or emailinfo@ sironadental.co.uk.

\section{CONSULT, LEARN AND GROW WITH BUSINESS IQ}

New for 2015, Business IQ is a new initiative that has been developed to positively impact the profitability of dental practices by offering a range of products and services to either help increase revenue or reduce costs.

Bringing together the core service offerings from Software of Excellence and Henry Schein Dental, along with expertise from a range of third party partners, Business IQ aims to improve your business performance through a range of practical solutions, under the headings: Consult, Learn, Grow.

Consult: finding a trusted advisor for your business can be difficult. Whether you want to benefit from the business tools within EXact from Software of Excellence, want to explore the latest digital restorative solutions or are thinking about refurbishing your practice, Business IQ has a solution to help.

Learn: ensure your team are up to date with training and Core CPD. Through Business IQ you'll be able to choose from a wide range of clinical and non-clinical courses that will help to improve both practice and personal development.

Grow: from reduced rates on recruitment and financial advice, through to all aspects of practice marketing, including patient literature and developing patient engagement through social media, Business IQ has a range of solutions to help your practice grow.

To see how Business IQ can help your business grow and prosper call us on 08000232558 or visit www.hsbusinessiq.co.uk. 